\title{
EXPLAINING THE GAP BETWEEN ENROLLMENT AND EMPLOYMENT IN COMPUTER INFORMATION SCIENCES
}

\author{
William Oliver, Washburn University,william.oliver1@washburn.edu \\ Nathan Purcell, Washburn University,nathan.purcell@washburn.edu \\ Sergio Salas, Washburn University, sergio.salas@washburn.edu \\ RoryMacDonald, Washburn University,rory.macdonald@washburn.edu \\ Dr.WenyingSun, Washburn University,nan.sun@washburn.edu
}

\begin{abstract}
In this study we investigated why people choose computer information sciences majors as well as what deters people from the computer information sciences field. With this information we hoped learn what could be done to get more people interested in the field in order to fill the numerous amounts of jobs that require a computer information sciences background. We gathered data through an online survey that divided participants up into groups of people who are already a computer information science major and those who were not. After the survey was completed we analyzed the results to determine what aspects of the field were attracting people and what parts were causing people to choose a different major. We found significant differences in the demonstration of interest in the field, belief in a requirement of detailed technical knowledge, and willingness to solve problems. We did not find significant differences in areas such as the belief of having to always work alone, the concern of inadequate pay, and women's capability to succeed in the computing field.
\end{abstract}

Keywords: Computer Information Sciences, Enrollment, Employment, Job Market, Education

\section{INTRODUCTION}

Finding out what attracts people into a Computer Information Sciences education is a question organizations and individuals have been trying to answer for years. Why some people choose to enter the field, and why others don't is a question that could benefit the Computer Information Sciences field as well as the companies that employ graduates with a degree in Computer Information Sciences. The Bureau of Labor Statistics predicts a demand of 1.4 million computing jobs by 2020 , but only 400,000 computer science graduates [7]. Learning why there is such a high demand for workers but not as strong interest in the computer information sciences field is an important question to answer and would benefit our economy and school systems. If we can learn what attracts students to the field, and clear out misconceptions that keep others away, we'll be able to reduce the discrepancy between jobs and graduates.

Computer Information Sciences including computer science, information systems, information technology, and computer engineering was a field that saw expansive growth in the late 1990s and early 2000s. There was an average of 400 computer science majors per department in 2001 and 2002 but around 2007 we saw the average drop to 200 [9]. Since the large drop, we have seen the number of Computer science majors grow back to where it was in 2001[9]. Why have we seen the recent rise in computer science major declarations? One of the answers lies in the field's ability to employ just about anyone who is able to graduate with a bachelor's degree or higher. But even with the current status of the job market, there aren't enough graduates to fill the open positions in the industry.

Some have asked why such a booming field wouldn't be attractive to those who wish to have a job that is reliable and lucrative. Their reasons include an incorrect perception of what computer scientists do, lack of familiarity with the subject, and a misunderstanding of what computer science majors learn. A large percentage of students believe that if they were to major in CIS, they would be put in front of a computer left to code every day[5]. In reality, these jobs require an ability to communicate and work with others because much of work is completed in teams. These misconceptions lead to people believing that they do not have a future in computer science when many would be a 


\section{Issues in Information Systems}

Volume 16, Issue I, pp. 210-218, 2015

great fit for the job. We hope to identify drivers and misconceptions by answering the following two research questions:

1. Why do people choose to study or not study Computer Information Sciences?

2. What changes and misconceptions could be addressed in order to increase enrollment to match the demands of the job market?

We intend to learn what attracts people to the computer science field and what keeps them away. These questions are important to answer because if we can learn what brings people to CIS or even, what makes them hesitant to learn about CIS, we will be able to gradually decrease the gap between the CIS enrollment and the CIS job market.

The rest of the paper is organized as follows. We first present a brief literature review on studies that have been conducted on this topic. We then explain the methodology we use to conduct the two studies. Next we present the results. Finally, we discuss the implications of our results and the limitations of our research.

\section{LITERATURE REVIEW}

Previous studies have shown that the rate of enrollment into CIS majors in college was dropping while the job market, viability, and pay were all rising [4]. Most of the papers agreed with that fact that, as a whole, the public is largely misinformed about what CIS truly is $[6,2,4,5]$. The most prevalent thing keeping people from the field was the negative connotations associated with it, which are mainly driven by social media, educational advisory positions, and a lack of early exposure to the field [6]. Another fact learned is that CIS is not viewed as an intellectual discipline used to improve your basic understanding of the universe, such as math or physics, but as an accomplishment to be flaunted [2]. Most of these papers used a survey with questions concerning their understanding of the CIS field as a whole. Some of the papers also used job market studies to obtain a large-scale view of the job market, while others conducted enrollment studies to show the enrollment trend in CIS majors. Following are more detailed findings from the previous research.

Lewis, Jackson, and Waite [2] feature a survey from which we draw many of our questions. This paper uses the survey to compare the beliefs of faculty and several years of CIS students ranging from first years, second years, and seniors. The survey results show many of the beliefs between these groups align with one another. A few of the ones that conflict however are strange. For one of the most important questions, "Anyone could succeed at CS if they worked at it", faculty believed this question to be false with over $75 \%$ of them disagreeing with it. When compared to the students both lower year and higher year agreeing with this statement. The other worrying thing promoted by this paper is that CS is not promoted as an intellectual discipline used to understand the complexities of the world but as an accomplishment akin to a medal.

Pollacia, Lomerson, and Russel [4] conducted a study to improve enrollments in the CIS field by trying to increase the number and availability of CIS minors instead of trying to increase the amount of majors in the field. This study put forth some inventive ideas about creating more flexible minors instead of minors just being a minimized version of the major. Instead of being forced to take the first five classes that a major would instead they could take three CIS courses out of several beginner courses and some other related courses such as graphic design. This would improve CIS enrollment in general because of the permeation of computers in everyday life as well as diversify the field by allowing other disciplines to have a taste of what CIS is instead of making it their major.

Pollacia [4] puts forth the question of why there is a decline in CIS majors and if it is because of their perception of the IT profession. This paper first analyzed the number of CIS majors from 1971-2004 and it shows a sharp increase in the 1980's and after a short time quickly dipped down and this trend repeats in 1998. This paper uses a survey to ask faculty at universities what they believe is the reason for the decline in CIS enrollment. Out of the participants that took the survey, $67 \%$ believed it was outsourcing. The author also conducted another survey which asked students about their understanding of the major. The results showed that a massive number of them were incredibly misinformed of the major believing it to be a weak field. The paper then goes on to disprove all of the student's 


\section{Issues in Information Systems}

Volume 16, Issue I, pp. 210-218, 2015

notions using the National Bureau data to show that network systems and such fields are the second fastest growing in the US. The paper determined that students did not join the major due to misinformation and misunderstanding that they absorbed from social media such as televisions and self-generated opinions. Students shied away from CIS majors because of their strong negative beliefs of the field. Many of them were also highly dissatisfied with their counseling experience, although this paper deems this to not be the cause.

Carter [6] attempted to find out why students who have an aptitude for CS do not choose it as a major. This study uses a survey to determine why senior high-school participating in Calculus and Pre-Calculus do not choose CIS as a major and also asks questions about their understanding of the CIS field such as what are their perceptions of the field and what influences them the most. The survey also splits the results into male and female to check if gender makes a difference. The study showed that students viewed the CIS majors as people who would sit in front of the computer all day. As a whole it found that the image of computer science was what kept people from joining. Another fact gleaned from the survey was that pre-college education and classes for the CIS field was limited - only $8 \%$ of those surveyed have taken a CIS related class. This paper also found that the students understood there was money to be made in the field but it had no significant influence on their choices.

The literature we found addressed only one side of our questions. They asked either "Why is CIS enrollment lower than it should be" or "How is such a prosperous job market not completely filled." The information we found did not address the question of why there is such a large gap between enrollment and employment. We believe our research presents a necessary link between the two questions.

\section{METHODOLOGY}

To answer our research questions, we conducted two studies. In our first study we analyzed data on enrollment and employment trends in computer science fields. To analyze enrollment statistics we used the 2012-2013 Computing Research Association's Taulbee Survey on computing degree and enrollment trends. The Taulbee Survey annually collects data on trends in student enrollment and degree production from academic units that grant degrees in Computer Science, Computer Engineering, Information Science, Information Systems, Information Technology, Informatics, and related disciplines. Employment trends were analyzed using projections from the Bureau of Labor Statistics which documents the number of computing jobs by field in the market as well as new job openings over the next decade. We compared the results of these two studies to determine the size of the gap between available jobs and graduating students entering the market. We then created a graph displaying each trend to show how they measure with each other. If the employment projections exceeded the enrollments trends, we know that the number of new workers entering the job market will be unable to fill the replacement and growth of the occupation.

For our second study we developed a survey designed to determine college students' perceptions of the computer science field. To design the survey we investigated past research done on students' perceptions of the computer science field. We compiled a list of questions to determine why students may or may not be interested in the field and that could further explain the results of our first study. The survey targeted two categories of students, computer science majors, and non-computer science majors. The first few questions of the survey were used to determine which category the survey taker is in, and displayed the appropriate version of the survey, which differ by a few questions. The questions in the survey ask about the participant's feelings on different aspects of computer science like its importance, the professional field, and its study. These questions were used to determine things like misconceptions, or factors that steer potential students away from the field. The responses for the questions are an interval scale from strongly disagree (1) to strongly agree (7) and neutral (4). Most questions were derived from previous studies, and a few open ended questions were provided to allow detailed and personal responses. Responses were compared using an independent sample t-test between the major and non-major group to determine the difference in their responses and which questions, if any, yielded a significant difference. Respondents were approached and asked to voluntarily participate in the survey. CIS majors were specifically approached during CIS classes to participate, while non majors were approached at random. A copy of the survey instrument is listed in Appendix A. 
Issues in Information Systems

Volume 16, Issue I, pp. 210-218, 2015

\section{RESULTS}

This section presents the results of our study on CIS enrollment and employment trends as well as the results of the survey in study 2 .

\section{Enrollment Trends and Job Market Research}

Figure 1 is a graph generated based on data from the Taulbee Survey on Computing Degree and Enrollment trends [9]. It suggests undergraduate enrollment in computing majors has been increasing for the last 6 years. Over this year enrollment among U.S. computer science departments rose $13.4 \%$. Bachelor's degree production has increased 9.4\% continuing an increase for the fourth straight year. The fraction of women enrolled has increased from $11.7 \%$ to $14.2 \%$. From 2000 to 2007 enrollment rates steadily fell by half before picking back up. At this point it has caught back up to its numbers of 2000. It seems as of this point the enrollment rate will continue to increase.

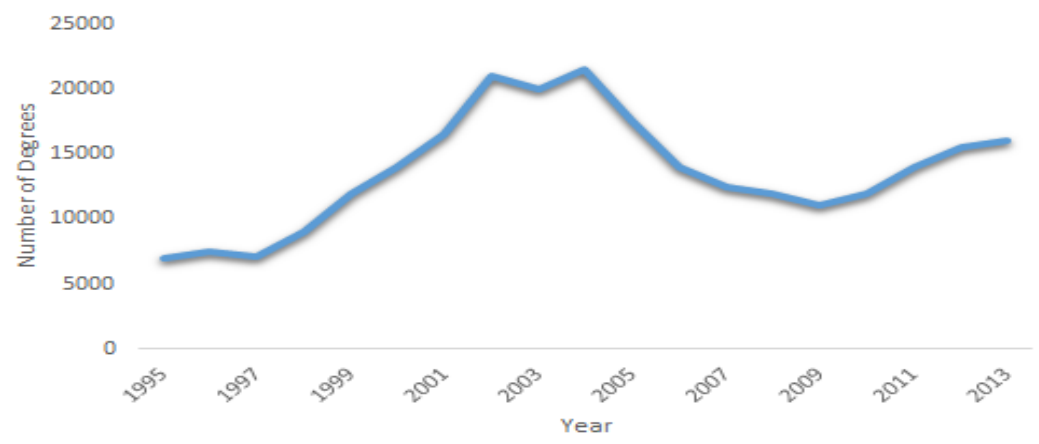

Figure 1. Enrollment Trend

The Bureau of Labor Statistics shows an 11.9\% increase in the number of people employed with a computing job since 2009, but predicts that there will be 1 million more computer science jobs than there are students over the next 6 years. Over the past 5 years, we have seen an increase in both the number of people employed and the mean wages of jobs that are in the CIS field as displayed in Figure 2 and Figure 3. Out of the various jobs we've researched, the software developer position shows the greatest increase in both pay and number of people employed, with the pay beginning at $\$ 90,170$ and increasing to $\$ 96,260$ and the number of people employed beginning at 495,500 and increasing to 643,830 over the course of a 5 year time period. All of the other jobs show similar patterns of change but not increasing at quite the same rate. CIS Research positions offer high pay but employ the lowest amount of people. Computer programmers, one of the more popular CIS positions, has seen a steady increase in pay but a slight drop in the number of people employed. Database Administrators employ a low amount of people, similar to CIS Researchers, but have almost identical patterns in pay to a programming position [7]. 


\section{Issues in Information Systems}

Volume 16, Issue I, pp. 210-218, 2015

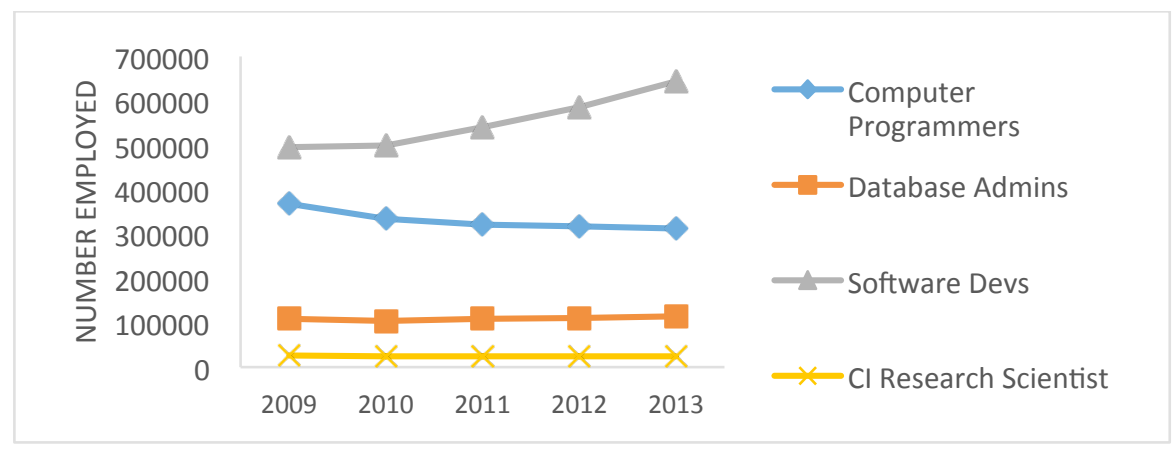

Figure 2. CIS Job Trends

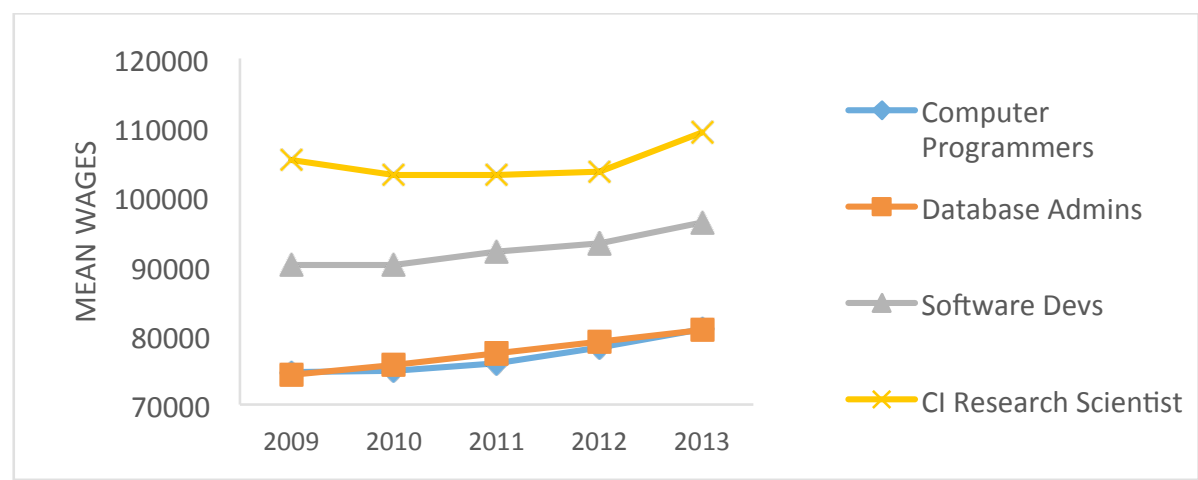

Figure 3. CIS Job Wage Trend

\section{Survey}

Data collection is still in progress. The results reported in this paper is based on what we received thus far. There are 89 total respondents, out of which 41 percent were computer information sciences majors. 75 percent of the participants were between the ages of 18 and 24.69 percent were male and 31 percent female. Of all non CIS majors 54 percent were male and 46 percent were female. The results for CIS Majors however measured $91 \%$ male and $9 \%$ female. Table 1 is the demographics of the respondents.

Table 1. Demographics of the Respondents 


\section{Issues in Information Systems}

Volume 16, Issue I, pp. 210-218, 2015

\begin{tabular}{|l|l|l|}
\hline \multicolumn{3}{|l|}{ Computer Science Major } \\
\hline Yes & 33 & $41 \%$ \\
\hline No & 48 & $59 \%$ \\
\hline
\end{tabular}

\begin{tabular}{|l|l|l|}
\hline \multicolumn{3}{|l|}{ Status } \\
\hline Student & 71 & $79.98 \%$ \\
\hline Part Time Worker & 41 & $46.07 \%$ \\
\hline Full Time Worker & 17 & $19.10 \%$ \\
\hline
\end{tabular}

\begin{tabular}{|l|l|l|}
\hline \multicolumn{3}{|l|}{ Age } \\
\hline 18 & 1 & $1.12 \%$ \\
\hline $18-19$ & 16 & $17.98 \%$ \\
\hline $20-21$ & 28 & $31.46 \%$ \\
\hline $22-24$ & 22 & $24.72 \%$ \\
\hline $25-30$ & 11 & $12.36 \%$ \\
\hline $31-40$ & 4 & $4.49 \%$ \\
\hline$>40$ & 7 & $7.87 \%$ \\
\hline
\end{tabular}

\begin{tabular}{|l|l|l|l|}
\hline \multicolumn{3}{|l|}{ Gender } \\
\hline All & Male & 61 & $69 \%$ \\
\hline & Female & 28 & $31 \%$ \\
\hline CIS Major & Male & 30 & $91 \%$ \\
\hline & Female & 3 & $9 \%$ \\
\hline Non CIS Major & Male & 26 & $54 \%$ \\
\hline & Female & 22 & $46 \%$ \\
\hline
\end{tabular}

The responses to the first set of questions were split into two groups, CIS majors and non CIS majors. We compared the mean responses for each question and determined the difference between the two groups. Only three questions had a significant difference between the groups in their response. These questions and their results are shown in Table 2 .

Table 2. Perceptual Differences

\begin{tabular}{|l|c|c|c|c|c|}
\hline \multicolumn{1}{|c|}{ Question } & $\begin{array}{c}\text { CS } \\
\text { Major } \\
\text { Mean }\end{array}$ & $\begin{array}{c}\text { Non CS } \\
\text { Major } \\
\text { Mean }\end{array}$ & SE & t-score & p-value \\
\hline $\begin{array}{l}\text { Q12. The work in computer science requires detailed } \\
\text { technical knowledge of how computers work. }\end{array}$ & 4.636 & 5.292 & -.655 & -2.002 & .049 \\
\hline Q13. I think computer science is interesting. & 6.545 & 4.938 & 1.608 & 5.894 & $<.001$ \\
\hline $\begin{array}{l}\text { Q15. I would rather have someone give me the solution to } \\
\text { a difficult problem than to have to work it out for myself. }\end{array}$ & 2.242 & 3.042 & -.799 & -2.714 & .008 \\
\hline
\end{tabular}

For question 12, CIS majors answered with a mean of 4.6 indicating a neutral to slightly agree response, and nonmajors answered with a 5.3 indicating a slightly agree to agree response. Question 12 displayed the most significant difference between the two groups. When asked if they found Computer Science interesting CIS majors responded with a 6.5 indicating agree to strongly agree, and non-majors responded with a 4.9 indicating neutral leaning heavily towards slightly agree. Finally for question 15 CIS majors indicated they disagree with a 2.2 while non CIS majors were more likely to say they only slightly disagreed with a 3.

The rest of the set of questions that did not reveal a significant difference in perception are listed below in Table 3 . The majority of these questions had the results we expected in terms of which group would be higher or lower, for instance majors agreeing more than non-majors that they could earn a living in programming, or that computer science was a worthwhile field. However these differences were not large enough to draw any conclusions from.

Table 3. Similar Perceptions

\begin{tabular}{|l|c|c|c|c|c|}
\hline \multicolumn{1}{|c|}{ Question } & $\begin{array}{c}\text { CS } \\
\text { Major } \\
\text { Mean }\end{array}$ & $\begin{array}{c}\text { Non CS } \\
\text { Major } \\
\text { Mean }\end{array}$ & SE & t- score & p-value \\
\hline $\begin{array}{l}\text { Q1. Nearly everyone is capable of succeeding in the computer } \\
\text { science curriculum if they work at it. }\end{array}$ & 4.576 & 4.625 & -.049 & -.138 & .891 \\
\hline Q2. To learn computer science you just need to memorize & 2.333 & 2.917 & -.583 & -1.785 & .078 \\
\hline
\end{tabular}




\section{Issues in Information Systems}

Volume 16, Issue I, pp. 210-218, 2015

\begin{tabular}{|l|c|c|c|c|c|}
\hline solution problems. & & & & \\
\hline $\begin{array}{l}\text { Q3. Doing well in computer science does not require a student } \\
\text { to spend most of his/her time at a computer. }\end{array}$ & 3.719 & 3.417 & .302 & .886 & .378 \\
\hline $\begin{array}{l}\text { Q4. A student who performs well in computer science will } \\
\text { probably not have a life outside of computers. }\end{array}$ & 1.970 & 2.375 & -.405 & -1.418 & .160 \\
\hline $\begin{array}{l}\text { Q5. Research in computer science often develops really } \\
\text { important ideas. }\end{array}$ & 5.667 & 5.667 & .000 & .000 & 1.00 \\
\hline Q6. Computer science is a worthwhile and necessary subject. & 6.152 & 5.917 & .235 & .880 & .381 \\
\hline $\begin{array}{l}\text { Q7. Knowledge of computing skills will not help me secure a } \\
\text { good job. }\end{array}$ & 1.727 & 2.042 & -.314 & -1.145 & .256 \\
\hline $\begin{array}{l}\text { Q8. In the real world computer scientists spend a lot of time } \\
\text { working alone. }\end{array}$ & 2.818 & 3.063 & -.244 & -.812 & .419 \\
\hline $\begin{array}{l}\text { Q9. In the real world computer scientists' work is mostly } \\
\text { programming. }\end{array}$ & 3.152 & 3.479 & -.328 & -1.195 & .236 \\
\hline $\begin{array}{l}\text { Q10. The work in computer science in the real world requires a } \\
\text { lot of creativity. }\end{array}$ & 5.182 & 4.854 & .328 & 1.415 & .161 \\
\hline Q11. You can earn a living in programming. & 6.394 & 6.021 & .373 & 1.380 & .171 \\
\hline $\begin{array}{l}\text { Q14. Women are just as able to excel in computing courses as } \\
\text { men. }\end{array}$ & 6.667 & 6.333 & .333 & 1.447 & .152 \\
\hline
\end{tabular}

For the final portion of the survey, we asked participants open-ended questions about their thoughts on the current misconceptions of CIS, their opinions on the majors, and what could be done to improve the field. We found some answers to be consistent among both groups. For CIS majors, the most popular of the responses about the misconceptions of the field were that the majority of the course material involved was programming work followed by prior exposure to the material before beginning the major was a necessity. Non-CIS majors were asked if they had ever considered enrolling in a CIS course or even declaring a CIS major. Of those who responded yes the answer that appeared most often for why they had considered it was because they were interested in the material and to supplement their current studies. For those who indicated they hadn't considered CIS, the most popular responses were again interest in the field, in this case a lack of, and second, that there weren't enough easily accessible introduction courses. The final question asked both groups what change they felt could be made to most positively impact enrollment in computer information sciences. The most answered response was the availability of CIS courses in High School with 82\% of respondents.

\section{DISCUSSION}

Our first research question asked "Why do people choose to study or not study Computer Information Sciences?" Our data suggests that the main factor that steers students away from CIS is a lack of interest. Most of our results from the survey were very similar except for three questions. Question 13 of our survey "I think computer science is interesting." may be the main reason for this lack of interest in CIS. A few people have a significant amount of exposure to CIS content before and during their college career. They may not be sure what someone with a job in the CIS field would do nor what to expect out of a CIS class.

Our second research question asked "What changes and misconceptions could be address in order to increase enrollment to match the demands of the job market?" Our data suggests that non CIS majors may have a fixed notion of what it takes to go into CIS which may deter them from taking a CIS class. Question 12 of our survey asked "The work in computer science requires detailed technical knowledge of how computers work." The results of question 12 had a significant difference between the CIS majors and non CIS majors indicating that the non CIS 


\section{Issues in Information Systems}

Volume 16, Issue I, pp. 210-218, 2015

majors would agree more often than the CIS majors. Question 12 may discourage students from enrolling in a CIS class because they were not exposed to CIS early on and therefore, have no experience.

From our first study, we learned that even with enrollment increasing we do not see it growing at a rate that meets the demands of the job market. The increase in enrollment tells us that students are in fact aware of the benefits that a CIS job can provide, but what our survey told us was that an overall lack of interest and an undeveloped understanding of the CIS field is keeping a large number of students from flocking to this field. Our study shows that there isn't a singular solution to this problem but we believe there are actions we can take to increase interest in CIS and hopefully bring enrollment rates up even higher than they are currently.

To narrow the gap based on the study results, it may be necessary to provide CIS high school courses as well as more introductory level college level courses. High school courses would allow students to learn about CIS at a younger age and before they are in college where they have to make a big decision of choosing a major. Here they would have easier access to the content, with no cost and a more open schedule for their choice of electives. At the college level, more accessible introductory courses would provide students with a low risk option to gauge their interest. Non majors would still be able to find worth in the class material if they chose to not major in CIS or are just looking to supplement their current major. As organizations become increasingly selective, CIS majors also need to be aware that they will have to obtain the necessary knowledge and skills in order to successfully fill the open positions in the industry. A CIS degree without the necessary knowledge will not travel far.

\section{LIMITATIONS AND FUTURE RESEARCH}

The limitations of our study include our sample size and the demographics of the participants. We have a total of 89 survey responses, which may not be a true representation of the overall population. Another aspect of the study that could have been improved was the fact that most participants were all students of the same university which restricts the kinds of answers we had the potential of getting. The final limitation we found with our study was that the answers given by CIS majors were all majors of the same CIS department of the same department, meaning that opinions or beliefs they've developed could be shaped by the similar exposures the CS work and faculty. However, the non CIS majors who responded to our survey came from several departments in the University. The respondents were of a diverse ethnicity as well as a range from freshman through seniors and contains various age groups.

For future research, we would recommend a significantly larger sample size spanning both the largest and smallest universities to obtain a better understanding of what the common belief is. We also believe it would be beneficial to design survey questions aimed at learning what could be done to increase interest in CIS or what people already find interesting about the field. This information could provide clarification on where the lack of interest stems from.

\section{REFERENCES}

1. Almstrum, V. L. (2003). What is the attraction to computing? Communications of the ACM, 46(9), 51-55.

2. Clayton L., M. H., William W., (2010). Student and faculty attitudes and beliefs about computer science.

3. Hoegh, A., \& Moskal, B. (2009). Examining science and engineering students' attitudes toward computer science. 39th ASEE/IEEE Frontiers in Education Conference. Available: http://www.fieconference.org/fie2009/papers/1035.pdf

4. Lissa, P. (2008). Improving CIS enrollments through flexible minors: An examination of existing curricula. Proceedings of the Eleventh Southern Association for Information Systems Conference

5. Lissa P., William L., \& Jack, R. (2007). Declining CIS majors and student's perceptions of the IT profession. Proceedings of the 2007 Southern Association for Information Systems Conference.

Lori C. (2006). Why students with an apparent aptitude for computer science don't choose to major in computer science. ACM SIGCSE Bulletin, 38(1), 27-31

6. Soper, T. (2014). Analysis: The exploding demand for computer science education, and why America needs to keep up. GeekWire. 


\section{Issues in Information Systems}

Volume 16, Issue I, pp. 210-218, 2015

7. Wiebe, E., Williams, L., Yang, K., \& Miller, C. (2003). Computer science attitude survey. Computer Science, 14(25).

8. Zweben, S. (2014). Computing degree and enrollment trends. CRA Taulbee Survey. Computing Research News 26(5).

\section{APPENDIX A: SURVEY INSTRUMENT}

What is your gender? Male Female

What is your age? $<18$ 18-19 20-21 22-24 25-30 31-40 >40

Which of the following best describes your current work status? Student, Part Time Worker, Full Time Worker

The scales are: $1=$ Strongly Disagree $4=$ Neutral $7=$ Strongly Agree, unless specified

Q1. Nearly everyone is capable of succeeding in the CIS curriculum if they work at it [2]

Q2. To learn computer science I just need to memorize solution problems [2]

Q3. Doing well in CIS does not require a student to spend most of his/her time at a computer. [3]

Q4. A student who performs well in CIS will probably not have a life outside of computers. [3]

Q5. Research in CIS often develops really important ideas [2]

Q6. CIS is a worthwhile and necessary subject. [8]

Q7. Knowledge of computing skills will not help me secure a good job. [3]

Q8. In the real world computer scientists spend a lot of time working alone. [2]

Q9. In the real world computer scientists' work is mostly programming. [2]

Q10. The work in CIS in the real world requires a lot of creativity. [2]

Q11. You could earn a living in programming. [8]

Q12. The work in CIS requires detailed technical knowledge of how computers work.

Q13. I think CIS is interesting. [3]

Q14. Women can excel in computing courses. [3]

Q15. I would rather have someone give me the solution to a difficult problem than to have to work it out for myself.

[8]

Q16. I have taken at least one CIS course.

Q17. I am a CIS major.

Q18. What are some misconceptions you had when you started your major?

Q19. What attracted you to the CIS major?

Q20. Have you ever considered a major in CIS or taking a computer science course? Why or why not?

Q21. What changes could be made to the CIS field to make it more attractive? 